response that manifests the probability [p. 132]." The fact that two equally probable responses, one being produced by instructing $S$ to accumulate a predetermined number of points, the other by giving $S$ the opportunity to listen to popular music, proved to have comparable reinforcement effects supports the indifference principle. Further supportive evidence for the indifference principle is the fact that changing the probability values of the two dissimilar reinforcing responses produced reinforced instrumental increments directly proportional to the probability value of the reinforcing response.

Premack (1963a) first advanced evidence for the indifference principle in a study where different probabilities of drinking and running, respectively, were produced by presenting Ss with different concentrations of sucrose to drink, and by manipulating the torque requirements of the activity wheel in which the Ss ran. When each of these differentially probable responses was made contingent upon an instrumental barpress response, barpressing rates paralleled the corresponding reinforcing response probability values. Instrumental response rate was thus associated with the ordered set of run and drink probabilities, but was independent of the nature of the response and the procedures used to alter the probability of response occurrence.

The demonstration of the indifference principle in two widely disparate species (rats and men), under widely disparate experimental conditions (drinking and running vs earning points and listening to music), suggests that the validity of the principle may be all-encompassing. If the capacity of the reinforcing response to reinforce instrumental responding is reducible to the common dimension of temporal duration, and precontingent temporal duration of the instrumental response is also shown to be a straightforward predictor of the outcome of the reinforcement relation (Bauermeister, 1970; Schaeffer, 1965), then the procedure of reinforcement may be shown to be remarkably less complex than many psychologists have imagined.

\section{REFERENCES}

Bauermeister, J. J. Positive reinforcement: Further tests of the Premack theory. Unpublished doctoral dissertation, Florida State University, 1970.

Premack, D. Prediction of the comparative reinforcement values of running and drinking. Science, 1963a, 139, $1062-1063$.

Premack, D. Rate differential in monkey manipulation. Journal of the Experimental Analysis of Behavior, $1963 \mathrm{~b}, 6,81-89$.

Premack, D. Reinforcement theory. In D. Levine (Ed.), Nebraska symposium on motivation, 1965. Lincoln: University of Nebraska Press, 1965. Pp. 123-180.

Schaeffer, R. W. The reinforcement relation as a function of instrumental response base rate. Journal of Experimental Psychology, 1965, 69, 419-425.

Wasik, B. H. Tests of the applicability of Premack's generalizations of reinforcement to human lever pressing behavior. Unpublished doctoral dissertation, Florida State University, 1967.

(Received for publication April 15, 1973.)

\title{
Operant responding in the common crow (Corvus brachyrhynchos)
}

\section{ROBERT W. POWELL \\ University of South Florida, Tampa Fla. 36620}

Common crows can be shaped to keypeck for food reinforcement, using conventional operant conditioning apparatus. They will respond for a variety of foods, but live mealworms and Prime dog food are the most effective of those studied here. The crow would appear to be an interesting avian species for study, because it possesses a number of more complex behavioral characteristics than the pigeon.

Despite periodic criticisms (Beach, 1950; Bitterman, 1960; Lockard, 1968), experimental psychologists continue to focus their research upon a very small number of species, principally the domesticated rat, the domesticated pigeon, and the rhesus monkey. One of the "neglected" species has been the crow, which some ornithologists believe to represent the most advanced stage of avian evolution (Thomson, 1964). The crow would appear to be a potentially interesting subject for study because of its complex social behavior
(Bannerman, 1963), its elaborate communication system (Chamberlain \& Cornwell, 1971), and ethological reports suggesting high intelligence (Lorenz, 1952).

The purpose of this report is to recount our experience in training common crows to keypeck for food, using conventional operant conditioning apparatus and procedures. As part of this research, we have investigated the relative effectiveness of a variety of food reinforcers for the crow.

\section{METHOD}

Training has been undertaken with 16 common crows (Corvus brachyrhynchos) so far. The crows were obtained from the Fur and Feather Game Farm, Neshkoro, Wisconsin. The birds had been taken from their nests as fledglings. They were maintained in the laboratory on a diet of dried dog food (Gaines Ken-L-Biskit), with water and grit (crushed granite) freely available. The crows were housed individually in a Bussey Products Fowl Battery. They were maintained under the same conditions as are appropriate for pigeons, except that each crow was provided with a perch, which it used frequently. Free-feeding weights, determined when each crow was approximately 6 months old, ranged from 330 to $552 \mathrm{~g}$. Johnston (1961) reports that the weight of adult crows in the wild ranges from 315 to $575 \mathrm{~g}$, depending upon sex and locality. 
Table 1

Free-Feeding Weight, Mean Weight During Training, Approximate Age When Training Was Initiated, and Number of Training Sessions for Each Crow

\begin{tabular}{|c|c|c|c|c|c|}
\hline Ss & $\begin{array}{c}\text { Free- } \\
\text { Feeding } \\
\text { Weight (g) }\end{array}$ & \multicolumn{2}{|c|}{$\begin{array}{l}\text { Training } \\
\text { Weight }\end{array}$} & $\begin{array}{c}\text { Training } \\
\text { Age } \\
\text { (Months) }\end{array}$ & $\begin{array}{c}\text { Number of } \\
\text { Training } \\
\text { Sessions* }\end{array}$ \\
\hline 1 & 392 & 309 & 79 & 8 & $\dagger$ \\
\hline 2 & 413 & 365 & 88 & 6 & $1 / 2$ \\
\hline 3 & 552 & 460 & 83 & 6 & $1 / 11$ \\
\hline 4 & 385 & 313 & 81 & 6 & $1 / 17$ \\
\hline 5 & 450 & 340 & 76 & 6 & $13 / 22$ \\
\hline 6 & 430 & 336 & 78 & 4 & $1 / 1$ \\
\hline 7 & 425 & 334 & 79 & 4 & $0 / 0$ \\
\hline 8 & 430 & 374 & 87 & 3 & $2 / 5$ \\
\hline 9 & 420 & 357 & 85 & 3 & $2 / 3$ \\
\hline 10 & 525 & 377 & 72 & 3 & $2 / 4$ \\
\hline 11 & 450 & 362 & 80 & 4 & $2 / 3$ \\
\hline 12 & 330 & 270 & 82 & 4 & $3 / 2$ \\
\hline 18 & 439 & 360 & 82 & 6 & $1 / 7$ \\
\hline 21 & 500 & 412 & 82 & 8 & $t$ \\
\hline 30 & 390 & 315 & 81 & 9 & $5 / 26$ \\
\hline 45 & 385 & 263 & 68 & 8 & $2 / 17$ \\
\hline
\end{tabular}

A Lehigh Valley pigeon test chamber, Model 1519C, was employed. A force of $15 \mathrm{~g}(0.147 \mathrm{~N})$ or more was required to operate a microswitch attached to the response key. The opening to the food tray (hopper) was enlarged to accomodate the large bill of the crow. The surface area of the hopper, where food is available, was enlarged by removing the metal frame which covers all but the center of the hopper. The funnel-type opening through which food is available when the hopper is in the "up" position was removed also. It was replaced by a flat metal strip which covered the rear half of the area from which the funnel was removed. The metal strip prevented access to food when the hopper was in the "down" position. In addition, metal strips were added to each side of the hopper so as to increase its depth. Gaines Prime (beef variety) served as the reinforcer. Reinforcement time was $5.0 \mathrm{sec}$ for each bird during shaping and $3.0 \mathrm{sec}$ when the relative effectiveness of eight food reinforcers was studied.

Shaping by the method of successive approximation (Skinner, 1951) was the procedure used to train all crows. The crows first had one 30 -min session with no training procedure to allow for adaptation. Next, they had daily 30 -min sessions in which the food hopper was presented automatically for $5.0 \mathrm{sec}$ with $20 \mathrm{sec}$ between presentation, which continued until the bird was eating reliably from the hopper. Then 30 -min shaping sessions were initiated and continued until the animal made at least 20 responses in a session, which was the criterion for acquisition.

Five of the crows then received additional training under a continuous reinforcement schedule (CRF), until responding stabilized over five consecutive sessions. Responding was studied next under a CRF schedule for each of the following foods: Noyes pigeon pellets, Gaines Prime, shelled sunflower seeds, Mynah bird pellets, ${ }^{1}$ live mealworms, Purina mixed pigeon grain, Gaines Ken-L-Biskit (kibbled), and Niblets whole kernal yellow corn. Each food was studied until responding was stable over 5 consecutive sessions, providing that 10 sessions had been completed. The sequence of foods studied varied unsystematically between Ss, in order to control for sequence effects. All experimental sessions were $30 \mathrm{~min}$ in duration, which proved to be long enough for responding to always cease before the session terminated. In addition to number of responses, the amount of food eaten was determined through presession measurement of amount placed in the food hopper and postsession measurement of the amount remaining in the hopper, plus spillage within the test chamber.

\section{RESULTS AND DISCUSSION}

All 16 crows were shaped to keypeck, and there was considerable variation between Ss in the amount of time required to engender responding. The results presented in Table 1 suggest that training is more readily accomplished, the earlier it is initiated in the life of the crow. All of the crows trained at an age of 3 or 4 months quickly acquired responding, while the remaining crows, which were 6 to 10 months of age, required much more prolonged training, except for Crow 2. Differences in rate of acquisition seemed to be a function of marked differences in adaptation to the test chamber. The younger birds adapted readily, while the older birds seemed to experience great difficulty in adjusting to the new situation. They jumped up and down, flapped their wings, and banged against the sides of the chamber, often for the entire training session. This continued for a number of sessions in some cases, with Crows 5 and 30 showing the most severely disturbed behavior.

The age of the birds was determined on the assumption that since they had all come from the same locality (Wisconsin) they had all hatched at approximately the same time. Crows from that area nest in late April and May, and the eggs have an incubation period of 18 or 19 days (Johnston, 1961). Thus, a hatching date of May 15 was assumed for each crow.

Crows 1 and 21 were successfully shaped, but an accurate record of their training was not maintained. Crow 7 required no hopper training or shaping sessions, as this bird initiated consistent keypecking when placed in the test chamber for the adaptation session.

When responding for different foods was studied, the crows responded most often for Prime beef but ate larger amount of mealworms than any other food, as shown in Table 2. Mealworms produced the second highest number of responses, while corn was second in amount eaten, even though Crow 12 did not respond for corn at all. The fact that number of responses and amount eaten did not correlate highly shows that the crows were able to obtain larger amounts per reinforcement of some foods than others, since reinforcement times were the same in all cases. For example, they were able to obtain approximately $.25 \mathrm{~g}$ per reinforcement of corn, but only $.08 \mathrm{~g}$ per reinforcement of Prime. There were also marked individual variations in amount of food obtained per reinforcement, as exemplified by the large difference in responding between Crows 10 and 11, whereas the amounts eaten were generally similar for the two birds. The amount of food consumed per session generally corresponded to the weight of the crow.

While there was substantial inter-S consistency in apparent preference for the different reinforcers, there were also several striking idiosyncrasies. Most surprising, perhaps, was the failure of Crow 12 to respond for corn. Similarly, three of the crows responded little or not at 
Table 2

Number of Responses and Amount of Food Consumed Per Session Under the Deprivation Procedure*

\begin{tabular}{|c|c|c|c|c|c|c|c|c|}
\hline Ss & $\begin{array}{l}\text { Pigeon } \\
\text { Pellets }\end{array}$ & Prime & $\begin{array}{l}\text { Sunflower } \\
\text { Seeds }\end{array}$ & $\begin{array}{l}\text { Mynah } \\
\text { Pellets }\end{array}$ & $\begin{array}{l}\text { Meal } \\
\text { Worms }\end{array}$ & $\begin{array}{l}\text { Mixed } \\
\text { Grain }\end{array}$ & $\begin{array}{l}\text { Ken-L- } \\
\text { Bisket }\end{array}$ & Corn \\
\hline \multicolumn{9}{|c|}{ Responses Per Session } \\
\hline $\begin{array}{l}\text { C6 } \\
\text { C8 } \\
\text { C10 } \\
\text { C11 } \\
\text { C12 }\end{array}$ & $\begin{array}{r}51.4 \\
71.8 \\
39.0 \\
148.8 \\
57.2\end{array}$ & $\begin{array}{r}191.8 \\
147.8 \\
47.0 \\
182.8 \\
200.0\end{array}$ & $\begin{array}{r}115.0 \\
107.2 \\
53.0 \\
83.0 \\
62.6\end{array}$ & $\begin{array}{l}71.2 \\
78.0 \\
57.6 \\
90.8 \\
51.0\end{array}$ & $\begin{array}{r}198.4 \\
51.4 \\
86.0 \\
188.2 \\
99.2\end{array}$ & $\begin{array}{r}130.6 \\
34.6 \\
13.3 \\
206.2 \\
4.3\end{array}$ & $\begin{array}{r}192.2 \\
15.0 \\
94.0 \\
110.4 \\
117.4\end{array}$ & $\begin{array}{r}107.2 \\
37.0 \\
49.0 \\
221.2 \\
0.0\end{array}$ \\
\hline Mean & 73.6 & 153.9 & 84.2 & 69.7 & 124.6 & 77.8 & 105.8 & 82.9 \\
\hline \multicolumn{9}{|c|}{ Amount Eaten Per Session (g) } \\
\hline $\begin{array}{l}\text { C6 } \\
\text { C8 } \\
\text { C10 } \\
\text { C11 } \\
\text { C12 }\end{array}$ & $\begin{array}{r}11.4 \\
5.4 \\
16.8 \\
17.0 \\
5.4\end{array}$ & $\begin{array}{r}10.0 \\
9.0 \\
10.6 \\
17.0 \\
11.8\end{array}$ & $\begin{array}{r}10.4 \\
7.0 \\
7.6 \\
13.8 \\
6.2\end{array}$ & $\begin{array}{l}15.4 \\
10.6 \\
18.4 \\
16.4 \\
11.4\end{array}$ & $\begin{array}{l}34.4 \\
12.6 \\
26.0 \\
33.4 \\
22.2\end{array}$ & $\begin{array}{r}9.6 \\
1.0 \\
0.0 \\
21.4 \\
0.0\end{array}$ & $\begin{array}{r}11.6 \\
0.0 \\
10.8 \\
16.4 \\
12.8\end{array}$ & $\begin{array}{r}25.4 \\
14.4 \\
33.4 \\
31.2 \\
0.0\end{array}$ \\
\hline Mean & 11.2 & 11.7 & 9.0 & 14.4 & 25.7 & 6.4 & 10.3 & 20.9 \\
\hline
\end{tabular}

*The results are based upon the mean performance over the last five sessions for each reinforcer.

all for mixed grain, while Crow 11 ate more grain than any other food except mealworms and corn. Mixed grain was clearly the least effective reinforcer of those studied.

While the present results show that live mealworms is the most effective reinforcer, there are practical reasons to favor either Prime or Mynah pellets. All of the crows responded frequently and consumed substantial amounts of these reinforcers. Both reinforcers are readily available, require no refrigeration, and will last more or less indefinitely. Mealworms, on the other hand, must be kept in a suitable medium, and it is a time-consuming task to sort out the required number of worms each day.

As mentioned earlier, the crows had always ceased responding before the session terminated, indicating that they had reached a temporary state of satiation. There has been no directly comparable study with pigeons, but the findings of Reese and Hogenson (1962), who studied food satiation effects, appear relevant. They found that pigeons, which ranged in weight from $63 \%$ to $92 \%$ of their free-feeding weights, responded 200 to 400 times under a CRF schedule for $4.0 \mathrm{sec}$ access to mixed grain. These authors did not report the amount of food eaten, but we have observed that deprived pigeons usually eat 40 to $60 \mathrm{~g}$ of food in a short period of time under a CRF schedule. Thus, it appears that deprived pigeons respond more and eat more food in a relatively short period of time than do crows. The most obvious basis for this difference is that pigeons have a crop, while crows do not. The crop is an enlarged extension of the esophagus where food can be stored, and is found in Galliformes (fowl), Columbiformes (pigeons), Psittaciformes (parrots), and a few families among the Passeriformes (perching birds).

When conducting experiments involving food reinforcement with crows or other birds lacking a crop, these factors must be taken into consideration. Adjustments in food presentation time, session duration, or both must be made to aviod satiation effects.
The present results confirm the omnivorous character of feeding behavior in crows, while showing that some marked individual differences in this behavior do exist. From an ecological standpoint, the most important finding would appear to be the apparent preference of crows for live insect larva (mealworms). This finding suggests that crows, which have always been regarded by man as a pest, may contribute significantly to the control of insect populations, which is usually to man's benefit.

Our experience with the crow suggests that this bird can usefully be employed as an experimental S. It possesses a number of more complex behavioral characteristics than the pigeon, and would seem to represent a more advanced level of avian evolutionary development. Another positive consideration is the compatability of the crow with conventional experimental equipment.

\section{REFERENCES}

Bannermen, D. A. The birds of the British Isles. Edinburgh: Oliver \& Boyd, 1953.

Beach, F. A. The snark was a boojum. American Psychologist, $1950,5,115-124$.

Bitterman, M. E. Toward a comparative psychology of learning. American Psychologist, 1960, 15, 704-712.

Chamberlain, D. R., \& Cornwell, G. W. Selected vocalizations of the common crow. The Auk, 1971, 88, 613-634.

Johnston, D. W. The biosystematics of American crows. Seattle: University of Washington Press, 1961

Lockard, $R$. B. The albino rat: $A$ defensible choice or a bad habit? American Psychologist, 1968, 23, 734-742.

Lorenz, K. Z. King Solomon's ring: New light on animal ways. New York: Crowell, 1952.

Reese, T. W., \& Hogenson, M. J. Food satiation in the pigeon. Journal of the Experimental Analysis of Behavior, 1962, 5, 239-245.

Skinner, B. F. How to teach animals. Scientific American, 1951, 185, 26-29.

Thomson, A. L. (Ed.) A new dictionary of birds. New York: McGraw-Hill, 1964.

\section{NOTE}

1. Manufactured by Modern Pet Foods Co., Torrance, California 90503.

(Received for publication March 23, 1973.) 